\title{
Clinical Efficacy of Clonidine versus Fentanyl as Spinal Adjuvant to 0.5\% Hyperbaric Bupivacaine for Knee Arthroscopy under Subarachnoid Block- A Comparative Evaluation
}

\author{
${ }^{1}$ Professor, Department of Anaesthesiology and critical care, India \\ ${ }^{2}$ Resident, Department of Anaesthesiology and critical care, India \\ ${ }^{3}$ Assistant Professor, Department of Anaesthesiology and critical care, India \\ ${ }^{4}$ Professor, Anaesthesiology and critical care, India \\ ${ }^{5}$ Professor, Department of Anaesthesiology and critical care, India \\ ${ }^{6}$ Assistant Professor, Department of Anaesthesiology and critical care, India
}

Kumkum Gupta ${ }^{1 *}$, Shikha Agarwal ${ }^{2}$, Salony Agarwal ${ }^{3}$, Manish Jain ${ }^{4}$, Bhawana Rastogi $^{5}$ and Azka Zuberi ${ }^{6}$

Submission: November 03, 2016; Published: November 17, 2016

*Corresponding author: : Kumkum Gupta, Professor, Department of Anaesthesiology and critical care, 108-109, Chanakyapuri, Shastri Nagar, Meerut-250004, U.P, India, Email: kumkumprashant75@gmail.com

\begin{abstract}
Background: Neuraxial techniques are safe and possess many benefits with drawback of short duration of anesthetic action. A small mass of local anesthetic can produce profound and reproducible surgical anesthesia. The present was aimed to compare the clinical efficacy and safety of clonidine versus fentanyl as spinal adjuvant to $0.5 \%$ hyperbaric bupivacaine for knee arthroscopy.

Patients and Method: Sixty adult patients of American Society of Anaesthesiologists (ASA) physical status I and II of both genders, aged 18 to 58 years, were randomized into two groups of 30 patients each to receive either with $0.5 \mathrm{ml}$ of clonidine, $30 \mu \mathrm{g}$ (Group I BC) or $0.5 \mathrm{ml}$ of fentanyl, $25 \mu \mathrm{g}$ (Group II BF) with $3.5 \mathrm{~mL} 0.5 \%$ hyperbaric bupivacaine. Sensory and motor block characteristics and time to first rescue analgesic (i.v. tramadol $100 \mathrm{mg}$ ) were recorded as primary end points. Drug related side effects of pruritus, nausea, vomiting and respiratory depression were recorded as secondary outcomes.
\end{abstract}

Results: The onset of sensory and motor block, cephalic dermatome extension, and the time to two dermatome regression were prolonged in patients of clonidine group with statistical significant difference $(\mathrm{p}=0.039)$. Duration of analgesia was also extended in patients of clonidine group ( $283.00 \pm 40.18 \mathrm{~min}$ vs $231.50 \pm 46.18 \mathrm{~min}$ in fentanyl group) with statistically highly significant difference. Intraoperative hemodynamic changes were comparable and no medication was required. Mild pruritus observed in 5 patients of fentanyl group. Post spinal shivering, nausea, vomiting and respiratory depression did not occur in any patient.

Conclusion: Clonidine $30 \mu \mathrm{g}$ as spinal adjuvant to $0.5 \%$ bupivacaine was clinically more efficient than fentanyl for potentiating the block characteristics and enhancing the postoperative analgesia.

Keywords: Bupivacaine; Clonidine; Fentanyl; Knee arthroscopy; Subarachnoid block

\section{Introduction}

Subarachnoid block is commonly used regional anesthetic technique for patients who require surgical anesthesia for lower extremities, perineum, pelvic girdle or lower abdomen. It may be useful in patients with difficult airway or suffered from co-morbidities of severe respiratory disease. Spinal anesthesia covering the mid-thoracic level yields a contracted small intestine to provide superior surgical conditions in combination with profound muscle relaxation of abdominal muscles. 
Local anesthetic reversibly blocks the nerve conduction by blocking the sodium and potassium ion channels in the nerve membrane. Blockade of neural transmission in the posterior nerve root fibres interrupts somatic and visceral sensation and blockade of anterior nerve root fibres prevents efferent motor and autonomic outflow. Thus local anesthetic progressively inhibits the transmission of autonomic, sensory and motor impulses, resulting in sympathetic blockade, analgesia and anesthesia.

Subarachnoid blockade with $0.5 \%$ hyperbaric bupivacaine provides sensory and motor blockade for surgeries lasting for about 2 hours but co-administration of spinal adjuvants allow reduction in the required dose of local anesthetics with the advantage of generating the same degree of analgesia. Several adjuvants such as opioids and alpha- 2 agonists are used to enhance the onset and duration of spinal anesthesia and sedation along with their ability to provide enhanced post-operative analgesia [1].

The highly lipid soluble drugs such as fentanyl and sufentanil have a more rapid onset than hydrophilic opioids such as morphine. Fentanyl acts primarily as agonist at $\mu$-opioid receptors to produce analgesia of long duration and reduces the systemic toxicity by allowing dose reduction of local anesthetic. But this combination of local anesthesia with opioids may lead to undesirable effects of pruritus, nausea, vomiting, urinary retention and respiratory depression [2,3].

Alpha-2 adrenoceptor agonists are also used as spinal adjuvant. They act on pre-junctional and post-junction $\alpha-2$ adrenoreceptors in the dorsal horn of spinal cord. Clonidine is a centrally acting selective partial $\alpha 2$ adrenergic agonist and prolongs the duration of sensory and motor blockade by virtue of its ability to decrease sympathetic nervous system outflow. It increases the duration of analgesia, intensify the motor block and prolongs the duration of postoperative analgesia but it can cause hypotension and bradycardia [4].

Addition of clonidine or fentanyl has been shown to be beneficial, based on prior studies. In our place, the practice of spinal anesthesia does not include intrathecal clonidine, though clonidine is freely available. Intrathecal fentanyl is frequently administered but the availability of fentanyl is restricted. The present study may support the prior research of other countries.

The present prospective randomized double blind study was aimed to compare the clinical efficacy and safety of intrathecalclonidine versus fentanyl as adjuvant to $0.5 \%$ hyperbaric bupivacaine in patients undergoing knee arthroscopy.

\section{Patients and Method}

After approval from Institutional Ethical Committee and written informed consent, 60 adult patients of American Society of Anaesthesiologists (ASA) physical status I and II of both genders, aged 18 to 58 years, weighing 45-85 kg with height of 150-175 cm, scheduled for elective infraumblical surgery under subarachnoid block, were enrolled for present prospective randomized double blind study, conducted at Department of Anaesthesiology and Critical Care, Chattrapati Shivaji Subharti Hospital associated to Subharti Medical college, Meerut, India.

The patients with history of severe cardiac or pulmonary disease, poorly controlled hypertension, morbid obesity, neurologic disease, hepatic or renal dysfunction, metabolic disorders, and deformity of spinal column, bleeding or coagulation disorder, known hypersensitivity to study drugs or using any drug that modifies pain perception or infection at site of lumbar puncture were excluded from study. Refusal to technique and uncooperative patients were also excluded from study.

All patients were admitted prior to day of surgery and were premedicated with tablet alprazolam $0.5 \mathrm{mg}$ and tablet ranitidine $150 \mathrm{mg}$ on the night before surgery. Six hours fasting was ensured before the surgery.

All selected sixty patients were randomized into two equal groups of 30 patients each according to computer generated random number table. Patients of Group I were given intrathecal $3.5 \mathrm{~mL}$ of $0.5 \%$ hyperbaric bupivacaine with $0.5 \mathrm{ml}$ of clonidine $(30 \mu \mathrm{g})$ and patients of Group II were given intrathecal $3.5 \mathrm{~mL}$ of $0.5 \%$ hyperbaric bupivacaine with $0.5 \mathrm{ml}$ of fentanyl ( $25 \mu \mathrm{g})$. The total volume of drug was kept $4 \mathrm{~mL}$ to ensure the blinding of study. Study medication was prepared by an anaesthesiologist who was neither aware of the study protocol nor further involved for data collection.

After arrival in the operation theatre, standard monitors for heart rate, electrocardiogram, pulse oximetry and non-invasive blood pressure were attached for monitoring of vitals parameters. Intravenous line with $18 \mathrm{G}$ intracath was secured and lactated Ringer solution was infused at rate of $10 \mathrm{~mL} / \mathrm{kg}$ over 15 minutes, before initiation of subarachnoid block. Patients were instructed on the methods of sensory and motor assessments and were explained regarding the visual analogue scale (VAS) scoring system.

The subarachnoid block was carried out under all strict aseptic precaution in sitting position by midline approach at L2-3 or L3-4 intervertebral space using the 25 G Quincke's spinal needle. After identification of the correct space, $4 \mathrm{ml}$ of study drug solution was injected slowly according to group allocation. Immediately after intrathecal injection, the patient was made to lie supine and $10^{\circ}$ Trendelenberg tilt of table was done to achieve the adequate level of surgical anesthesia (T10 dermatome). All patients were supplemented with $100 \%$ oxygen at the rate of $4 \mathrm{~L} / \mathrm{min}$ via the venti face mask.

\section{Sensory and motor blockade characteristics}

All time intervals were calculated from the time of end of intrathecal injection. The sensory and motor block characteristics were assessed at 2 minute interval till the surgical anesthesia was achieved. The segmental level of sensory block was assessed by 
pin prick method bilaterally along the mid clavicular line using short bevelled 26 G hypodermic needle. The motor block of the lower extremities was evaluated bilaterally by modified Bromage Scale (0-3): 0 = full movement and able to raise straight leg against resistance; $1=$ unable to raise extended leg at the hip but able to flex knee; 2 = unable to flex the knee but able to move ankle joint; $3=$ unable to move hip, knee or ankle (no motor activity).

The onset time of sensory blockade at T10 dermatome, maximum cephalic dermatome level, and time taken to two dermatome regression of sensory analgesia were recorded. Time taken to achieve complete motor blockade and total recovery time from motor blockade was also recorded. The surgical anesthesia was considered when T10 dermatome was anesthetized.

Postoperatively the sensory and motor block levels were assessed at 15 minutes intervals until normal sensations are returned. Duration of sensory analgesia was taken from onset of spinal anesthesia to time of administration of first rescue analgesic, reflected on visual analogue scale (VAS $>3$ ).

VAS is a psychometric response scale and patients specified their level of pain by indicating a position along a continuous line between two endpoints of $0-10$ where $0=$ no pain to $10=$ worst possible pain.

\section{Hemodynamic parameters}

The hemodynamic parameters of systemic arterial pressure, heart rate, pulse oximetry and electrocardiography (ECG) were monitored preoperatively and then at every 5 minute intervals after initiation of subarachnoid block, till end of surgery and followed by at every 15 minutes interval in postoperative room. For the present study, hypotension was defined as systolic blood pressure of less than $20 \%$ of base line value or less than $100 \mathrm{~mm}$ $\mathrm{Hg}$. It was treated primarily by increasing the rate of infusion and additionally with bolus of mephenteramine $6 \mathrm{mg}$ intravenously if required further. Bradycardia was defined as heart rate less than 60 beats per minute and was treated with intravenous atropine $0.6 \mathrm{mg}$.

\section{Level of sedation}

The sedation score was evaluated by Ramsay Sedation Scale at every 30 minutes considering the time of giving the study drug as zero. Ramsay Sedation Scale: 1-Patient anxious, agitated or restless; 2. Patient co-operative, oriented and tranquil alert; 3-Patient responds to commands; 4-Asleep but arousable with brisk response; 5-Asleep with sluggish response; 6-Asleep with no response.

\section{Adverse events}

All patients were observed for pruritus, nausea, vomiting, respiratory depression (defined as respiratory rate less than 10 breaths/ minute), shivering or any other adverse effects. Respiratory discomfort was managed by increasing the flow of oxygen. Nausea and vomiting was treated by intravenous ondansetron (4 mg).
After the end of surgery, the patients were shifted to the recovery room and monitored for any changes in vital signs. Postoperative analgesia was monitored at every 15 minutes interval for the 1st hour and then at every 30 minute interval for next two hours. Rescue analgesia was given with inj. tramadol $100 \mathrm{mg}$ with ondansetron $4 \mathrm{mg}$ intravenously when VAS score was $\geq 3$.

\section{Study Population Size}

The sample size was calculated with standard computer programme which computed that approximately 23 to 25 patients should be included in each group in order to detect at least clinically significant difference of $30 \mathrm{~min}$ in mean duration of postoperative analgesia between the groups for type 1 error of 0.05 with power of $80 \%$ and $95 \%$ confidence limit. Assuming a $5 \%$ drop out rate, the final sample size was set at 60 patients for better validation of results.

\section{Statistical analysis}

The results obtained in the study are presented in a tabulated manner as Mean \pm Standard Deviation (SD) considering the later as the best predictor for statistical analysis. Data was analyzed using Stat graphic centurion, version 16 (Stat point Technologies INC, Warrenton). The demographic data for categorical variables were compared using chi-square test and statistical significance in mean difference was done by using analysis of variance (ANOVA). A p value of $<0.05$ was considered to indicate statistical significance.

\section{Results}

The present study compared the clinical efficacy and safety of clonidine versus fentanyl as spinal adjuvant to $0.5 \%$ hyperbaric bupivacaine for subarachnoid block on 60 adult consenting patients. There was no protocol deviation and study was successfully completed. Data of all patients were included for statistical analysis. They were cooperative with subsequent assessment of subarachnoid block characteristics and VAS score.

The demographic data for age, weight, height, BMI, American Society of Anaesthesiologist (ASA) physical status classification and duration of surgery were comparable between the groups (Table 1).

Table 1: Showing Demographic Profile.

\begin{tabular}{|c|c|c|c|}
\hline Demographic data & Group I & Group II & P value \\
\hline Age (year) & $35.83 \pm 6.7$ & $39.66 \pm 15.09$ & 0.209 \\
\hline Weight (kg) & $55.23 \pm 10.65$ & $54.06 \pm 9.4$ & 0.655 \\
\hline Height(cm) & $164.6 \pm 5.37$ & $162.2 \pm 6.58$ & 0.128 \\
\hline BMI (kg/m2) & $21.35 \pm 2.51$ & $20.47 \pm 2.88$ & 0.894 \\
\hline ASA(I/II) & $28 / 2$ & $27 / 3$ & 0.64 \\
\hline Duration of surgery(min) & $128.45 \pm 6.31$ & $132.51 \pm 7.82$ & 0.526 \\
\hline
\end{tabular}

Data are expressed as Mean and Standard deviation (SD) or numbers; $P$ Value $>0.05$ is statistically non-significant. 


\section{Sensory blockade profile}

The mean time required to achieve complete sensory blockade was $1.94 \pm 1.06 \mathrm{~min}$ in patients of Group I and $2.45 \pm$ $0.78 \mathrm{~min}$ in patients of Group II with statistically significant difference $(\mathrm{P}=0.039)$. Mean maximal cephalic dermatome level was comparable between the groups. Mean time for two segment regression was $121.33 \pm 14.31 \mathrm{~min}$ in patients of Group I and $102.00 \pm 33.05 \mathrm{~min}$ in patients of Group II. The duration of two segment regression varied significantly between the groups $(p=0.05)$. Mean duration of sensory analgesia was $283.00 \pm 40.18$ min with clonidine and $231.50 \pm 46.18$ min with fentanyl and showed statistically significant difference $(\mathrm{P}=0.000)$ (Table 2).

Table 2: Showing Sensory and Motor Blockade Profile.

\begin{tabular}{|c|c|c|c|}
\hline Parameter/ Groups & Group I & Group II & p Value \\
\hline $\begin{array}{c}\text { Onset of complete } \\
\text { Sensory blockade } \\
\text { (min) }\end{array}$ & $1.94 \pm 1.06$ & $2.45 \pm 0.78$ & $0.039^{*}$ \\
\hline $\begin{array}{c}\text { Maximal cephalic } \\
\text { dermatome level }\end{array}$ & $7.1 \pm 1.06$ & $7.6 \pm 1.58$ & 0.157 \\
\hline $\begin{array}{c}\text { Mean time of } \\
\text { Two segment } \\
\text { regression(min) }\end{array}$ & $121.33 \pm 14.31$ & $102.00 \pm$ & $0.005^{*}$ \\
\hline $\begin{array}{c}\text { Duration of sensory } \\
\text { analgesia (min) }\end{array}$ & $283.00 \pm 40.18$ & $231.50 \pm 46.18$ & $0.000^{* *}$ \\
\hline $\begin{array}{c}\text { Onset of complete } \\
\text { motor block (min) }\end{array}$ & $2.8 \pm 1.2$ & $3.5 \pm 1.06$ & $0.021^{*}$ \\
\hline $\begin{array}{c}\text { Duration of motor } \\
\text { blockade (min) }\end{array}$ & $242.53 \pm 29.32$ & $188.50 \pm 40.06$ & $0.000^{* *}$ \\
\hline
\end{tabular}

Data are expressed as Mean and Standard deviation (SD); $P$ Value $<0.05$ is statistically significant; ${ }^{* *} P$ value $<0.001$ is statistically highly significant.

Mean time to achieve complete motor block was $2.8 \pm 1.2 \mathrm{~min}$ in patients of Group I and $3.5 \pm 1.06$ min in patients of Group II with statistically significant difference $(\mathrm{P}=0.021)$. Mean duration of complete motor block was $242.53 \pm 29.32 \mathrm{~min}$ in patients of Group I and $188.50 \pm 40.06 \mathrm{~min}$ in patients of Group II with statistically highly significant difference $(\mathrm{P}=0.000)$ (Table2).

\section{Hemodynamic profile}

The hemodynamic parameters of mean arterial blood pressure, mean heart rate, respiratory rate and oxygen saturation at baseline were comparable.

After 5 min of subarachnoid block (SAB), the mean heart rate and mean systolic blood pressure showed gradual decline in patients of both group until after 30 min of SAB [Graph 1,2]. After $5 \mathrm{~min}$ of subarachnoid block, the mean arterial pressure of all patients was decreased till 15 min with statistically highly significant difference. Later on, the mean arterial pressure (MAP) became stable in patients of both groups and the difference between the groups was comparable. [Graph 3] Incidence of hypotension and bradycardia during the intraoperative period was minimal and did not require any medical intervention.

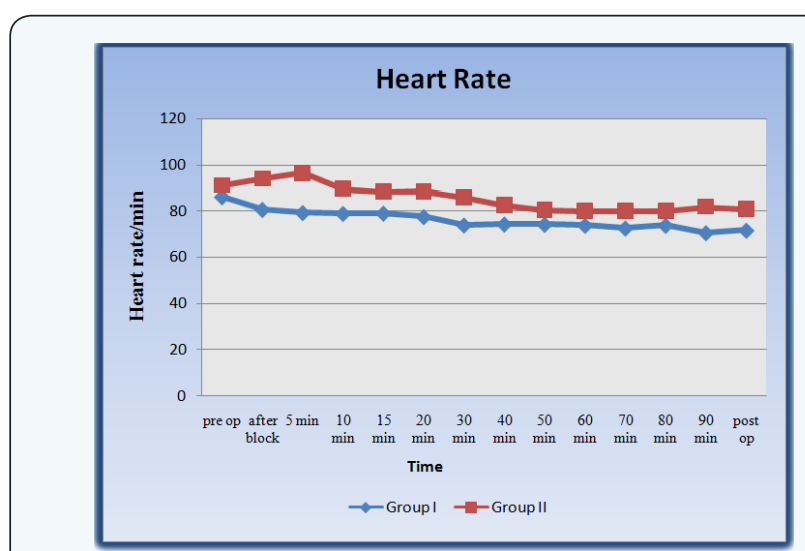

Graph 1: Showing changes in Heart Rate (beats/min).
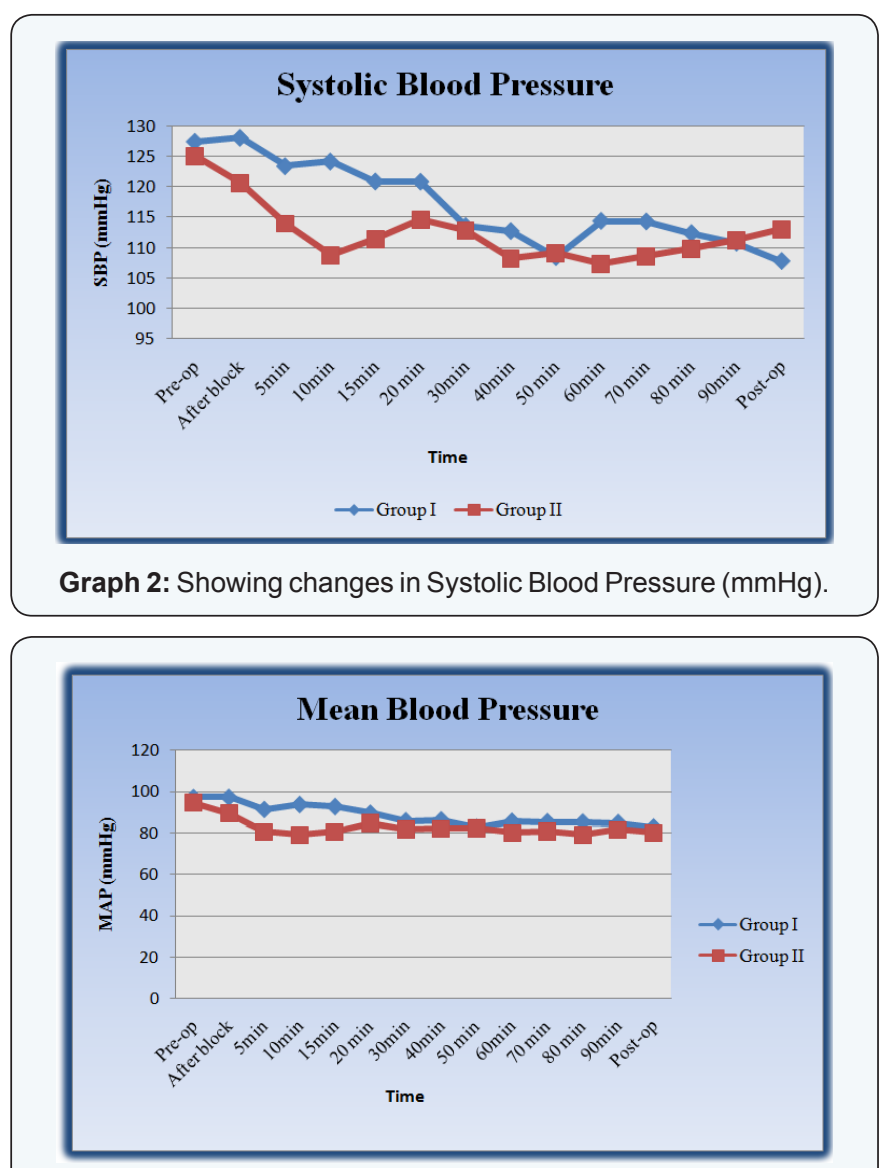

Graph 3: Showing changes in Mean Arterial Pressure $(\mathrm{mm} \mathrm{Hg})$.

Sedation score was recorded every $30 \mathrm{~min}$ for two hours, considering the time of study drug given as zero. Mean sedation score was $1.063 \pm 0.4$ in patients of Group I and $1.133 \pm 0.50$ in patients of Group II, which was comparable $(\mathrm{p}=0.606)$, which 
signifies negligible sedation by clonidine and fentanyl. All patients were calm and cooperative.

Mild pruritus was observed in 5(16.7\%) patients of Group II which was successfully treated with intravenous inj. phentermine. The respiratory rate in patients of both groups was comparable and no episodes of respiratory depression or tachypnoea occurred in either group. Peripheral oxygen saturation remained well within normal limits with mild fluctuations. No patient suffered from post spinal shivering, nausea, vomiting or respiratory depression. None of the patient needed supplemented analgesia during surgery.

\section{Visual analogue scale}

Visual Analogue Scale (VAS) in each patient of Group I and II was recorded every 15 minutes for first hour after surgery followed by every $30 \mathrm{mins}$ for next two hours. The difference in the intensity of pain was statistically highly significant between the groups. It was higher in patients of Group II. Rescue analgesia was not required in any patient till 3 hours after surgery [Graph 4].

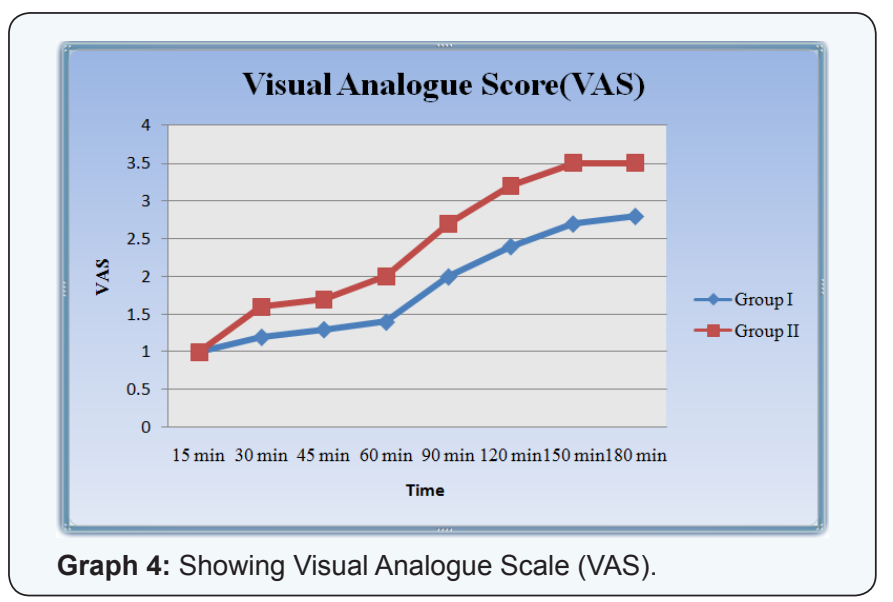

\section{Discussion}

Neuraxial anesthetic techniques are preferred for infraumblical surgeries due to rapid onset of surgical anesthesia and complete muscular relaxation. It is beneficial in patients of anticipated difficult airway or suffering from comorbid conditions such as respiratory diseases. The technique is simple, economical, and reproducible with reduction in the incidences of venous thrombosis. The postoperative analgesia can be extended by using spinal adjuvants without affecting their early mobilization.

In augmentation strategies wide variety of opioids and nonopioids are used as an adjuvant to subarachnoid block to improve the quality of block and surgical anaesthesia with prolongation of postoperative analgesia. Clinical studies have shown that opioids and alpha 2 adrenergic agonist administered intrathecally were able to relieve visceral pain [5].

In present study, 17.5mg hyperbaric bupivacaine was used to establish the subarachnoid block because10mg hyperbaric bupivacaineor less carry a risk of inadequate block as proven by Pederson et al while generous dosages guaranteed the effective surgical anesthesia [6]. In the present study we have used both clonidine and fentanyl as spinal adjuvant to hyperbaric bupivacaine and achieved a comparable higher level of sensory blockade. But the onset and duration of sensory and motor blockade showed statistically significant difference between the groups. The onset of sensory blockade was rapid and duration of sensory blockade was enhanced by clonidine when compared to fentanyl.

The clonidine is lipid soluble and easily penetrates the blood-brain barrier to provide effective and extended analgesia by binding to presynaptic C-fibres and postsynaptic dorsal horn neurons. Its analgesic action is a result of decreased release of C-fiber transmitters and hyperpolarisation of postsynaptic dorsal horn neurons. The prolongations of blockmay result from synergism between bupivacaine and clonidine to motor neurons in the dorsal horn. Intrathecal clonidine has antinociceptive action for both somatic and visceral pain.

In our study, clonidine in dose of $30 \mu \mathrm{g}$ was chosen which favoured the study of Prabha P et al. [7] They concluded that $30 \mu \mathrm{g}$ of clonidine has significantly increased the cephalic spread and duration of analgesia as compared to bupivacaine alone [7]. This is also supported by the study carried out by Chiari et al. [8]. These authors reported that the risk of hypotension is more with higher dosages of clonidine $(150 \mu \mathrm{g})$.

Fentanyl is a lipophilic $\mu$-receptor agonist opioid and intrathecal fentanyl exerts its affect by combining with opioid receptors in the dorsal horn of spinal cord with supra spinal spread to provide good perioperative analgesia. We used $25 \mu \mathrm{g}$ fentanyl in another group as spinal adjuvant to $0.5 \%$ hyperbaric bupivacaine for subarachnoid block. Ramchandra VS et al. [9] also concluded that intrathecal $25 \mu \mathrm{g}$ fentanyl to bupivacaine provides good analgesia with less sedation and is a better option where sedation is not desirable [9].

In present study, the sensory blockade profile was significantly better in patients with clonidine when compared to fentanyl. Similar results were also observed by Strebel et al. [10] GecajGashi et al. [11] and Singh et al. [12]. They all reported the rapid onset of sensory block in patients receiving intrathecal clonidine. The mean time of two segment regression and complete sensory blockade was also significantly prolonged with clonidine when compared to fentanyl. This was also in accordance to the study of Tilker et al. [13] who reported that the time taken for regression of sensory block was statistically higher in clonidine group [13].

In our study, the duration of postoperative analgesia showed statistically significant extension in patients of clonidine group as compared fentanyl group, which is also supported by the study of Strebel et al. [10] and Tilker et al. [13] The complementary action of local anesthetics and $\alpha-2$ adrenoreceptors agonists accounts for their profound analgesic properties. 
Gupta K et al. [14] studied the analgesic efficacy of intrathecal clonidine $30 \mu \mathrm{g}$ versus butorphanol $0.20 \mathrm{mg}$ during orthopaedic surgeries. Though both drugs have intensified the sensory block and increased the duration of analgesia but clonidine was considered as better alternative to opioids as spinal adjuvant for orthopaedic surgeries [14]. The onset of motor block was significantly earlier in patients of clonidine group and our results are similar to the studies conducted by Singh et al. [12] Strebel et al. [10] and Gecaj-Gashi et al. [11] However in the study conducted by Tilker et al, the onset time of motor block was comparable in patients of both the groups.

In our study, clonidine significantly prolonged the duration of motor block which is also supported by the studies of Elia et al. [15] and Jain et al. [16] who reported 0 pain score in clonidine with bupivacaine as compared to $0.5 \%$ bupivacaine alone [16]. The prolongation of the motor block of spinal anesthesia may be the result of binding of $\alpha 2$ adrenoreceptors agonists to the motor neurons in the dorsal horn.

Hypotension was observed in $1(3.3 \%)$ patient of clonidine group and $3(10 \%)$ patient of fentanyl group which was managed by increasing the rate of crystalloid solution infusion and no vasopressor medication was required. It could be due to adequate preloading prior to institution of subarachnoid block. Bradycardia did not occur in either group reflecting the safety of low doses of spinal adjuvant. The results of present study are in accordance with Singh et al [12] \& Nazareth et al. [17]. They also reported stable hemodynamic parameters in the groups receiving intrathecal clonidine and fentanyl. No significant changes in the respiratory rate and oxygen saturation were observed in any patients of both the groups.

Postoperatively, significantly lower VAS scores were observed in patients receiving intrathecal clonidine, indicating good postoperative analgesic effect. Our results are comparable to those of Strebel et al. [10] Merivirta et al. [18] and Tilkar et al. [13]. There was no incidence of post-spinal shivering, nausea and vomiting in either group. All patients were calm and comfortable.

\section{Conclusion}

Clonidine, $30 \mu \mathrm{g}$ as spinal adjuvant to $0.5 \%$ bupivacaine was clinically more efficient than fentanyl $25 \mu \mathrm{g}$ for potentiating the subarachnoid block characteristics and enhancement of postoperative analgesia. All patients were calm and cooperative during surgery and no respiratory depression occurred in any patient. The incidences of hypotension or bradycardia were comparable and needed no medical intervention.

\section{Limitation of Study}

The present study was conducted on patients with stable cardio respiratory status (ASA I\&II). These patients needed spinal adjuvants to enhance the duration of anesthesia with low dosages of local anesthetic drug.

\section{References}

1. Roussel JR, Heindel L (1999) Effect of intrathecal fentanyl on duration of bupivacaine spinal blockade for outpatient knee arthroscopy. AANA J 67(4): 337-343.

2. Fields HL, Emson PC, Leigh BK, Gilbert RF, Iversen LL (1980) Multiple opiate receptor sites on primary fibres. Nature 284(5754): 351-353.

3. Hindle A (2008) Intrathecal opioids in the management of acute postoperative pain. Continuing Education in Anaesthesia, Critical Care and Pain. Br J Anaesth 8(3): 81-85.

4. Maze M, Tranquilli W (1991) Alpha-2 adrenoceptor agonists: defining the role in clinical anaesthesia. Anaesthesiology 74(4): 581-605.

5. Forster JG, Rosenberg PH (2003) Clinically useful adjuvants in regional anesthesia. Curr Opin anaesthesiol 16(5): 477-486.

6. Pederson H, Santos AC, Seinberg ES (1989) Effects of varying doses of $0.5 \%$ hyperbaric bupivacaine on visceral pain during operations. Anesthesiology 69(1): 380-384

7. Prabha P (1982) The effect of addition of clonidine to low dose bupivacaine for unilateral Inguinal Herniorraphy: A randomized double blinded study. Sch J Anaesth 54: 409-414.

8. Chiari A, Lorber C, Eisenach JC, Wildling E, Krenn C et al. (1999) Analgesia and hemodynamic effects of intrathecal clonidine as a sole analgesia agent during first stage of labor: a dose-response study. Anesthesiology 91(2): 388-396.

9. Abhishek PB, Govind SD, Ramchandra VS, Bhavini BS, Smita S (2013) Comparison of clonidine and fentanyl as an adjuvant to intrathecal bupivacaine for spinal and postoperative analgesia in patients undergoing caesarean section. Srilankan J Anesthesiol 22(1): 15-20.

10. Strebel S, Gurzeler JA, Schneider MC, Aeschbach A, Kindler $\mathrm{CH}$ (2004) Small-dose intrathecal clonidine and isobaric bupivacaine for orthopedic surgery: a dose-response study. Anesth Analg 99(4): 12311238.

11. Gecaj-Gashi A, Terziqu H, Pervoefi T, Kryeziu A (2012) Intrathecal clonidine added to small dose bupivacaine prolongs postoperative analgesia in patients undergoing transurethral surgery. Canadian Urological Association Journal 6(1): 25-29.

12. Singh H, Yang J, Thornton K, Adolph HG (1995) Study on the effects of intrathecal fentanyl of the onset and duration of hyperbaric bupivacaine. Can J Aaesth 42(11): 987-991.

13. Tilkar Y, Bansal SA, Agnihotri GS (2015) A comparative study of intrathecal clonidine and fentanyl as adjuvants to bupivacaine in lower limb orthopedic surgery. Int J Med Sci Public Health 4(4): 458-462.

14. Kumkum Gupta, Manish Jain, Prashant K Gupta, Shikha Agarwal, KS Bhatia, et al. (2015) Clonidine versus Butorphanol as adjuvant to $0.5 \%$ hyperbaric Bupivacaine to enhance the onset and duration of subarachnoid blockade with postoperative analgesia during orthopedic surgeries-A randomized study. Glob Anaesth Periopr Med 2: $50-53$.

15. Elia N, Culebras X, Mazza C, Schiffner E, Tramer MR (2008) Clonidine as an adjuvant to intrathecal local anesthetics for surgery: systematic review of randomized trials. Reg Anaesth Pain Med 33(2): 159-167.

16. Jain PN, Gehdoo RP, Priya V (2003) Study of intrathecal clonidine for postoperative pain relief. Indpain 17: 1233-1236.

17. Nazareth M, Ghoshal P, Namshikar V, Gaude Y (2013) Addition of intrathecal fentanyl to bupivacaine clonidine mixture effect on quality of subarachnoid block and postoperative analgesia. Anesth Essays Res 7(1): 76-82. 
18. Mervivirta R, Kuusniemi K, Jaakkola P, Pihlajamaki K, Pitkanen M (2009) Unilateral spinal anesthesia for outpatient surgery: A comparison between hyperbaric bupivacaine and bupivacaineclonidine combination. Acta Anaesthesiol Scand 53(6): 78893.
Your next submission with JuniperPublishers will reach you the below assets

- Quality Editorial service

- Swift Peer Review

- Reprints availability

- E-prints Service

- Manuscript Podcast for convenient understanding

- Global attainment for your research

- Manuscript accessibility in different formats ( Pdf, E-pub, Full Text, Audio)

- Unceasing customer service

Track the below URL for one-step submission http://juniperpublishers.com/online-submission.php 